\title{
Reading Nablus' urban print: Towards an understanding of its morphology
}

\author{
Muath Taher, Jorge Correia \\ Escola de Arquitectura da Universidade do Minho, Campus de Azurém, Guimarães, Portugal \\ E-mail: muath_tahir@hotmail.com, jorge.correia@arquitetura.uminho.pt
}

\begin{abstract}
Nablus old center stands as a typical Arab city with a relevant geographical location. Successive historical periods distinguish its history - from Canaanite to Roman, Byzantine, Islamic, Crusader or Ottoman - till nowadays. This cultural diversity has layered chronological strata on its urban fabric. Therefore, diverse historical characteristics reflected in the city's urban morphology have undergone continued physical and functional transformations, not only gradually by time and various socio-cultural, economic or political factors, but also radically by earthquakes and war destructions. Present-day Nablus' physical image echoes a palimpsest of urban/social identities and an asset for a very sensitive collective memory. This paper examines the formation, evolution and constitution of the old city of Nablus by a retrospective analysis that searches the morphological momentum for each phase in articulation with a reflection around its historical meaning for the city. Methodologically, this study is conducted on both urban and architectural levels, surveying street hierarchy and plot distribution. This understanding will be extremely important for an accurate perception of this tissue in order to advocate for a concerned idea of the city's reconstruction, following recent urban annihilations. At a time when urban rehabilitation pushes plans for quick and immediate results, reading Nablus' urban morphology can work as the lacking tool for an instructed and operative regeneration.
\end{abstract}

Keywords: Nablus, Palestine, urban morphology, urban evolution.

\section{Introduction}

Cities can be read through its urban form and the built environment is a physical representation of people's everyday life, it is socially constructed and where several activates take place. Thus, it can act as a mediator that stores the socio-cultural signs (Halbwachs, 1950) and celebrate the society values and meaning (Moudon, 1997a). However, as a result of continued and dynamic interaction; between people and their place, built environment is under a constant evolution and transformation. With time, layers of history have accumulated in the urban fabric. Specifically, this can clearly be realized in traditional old towns, which were constructed in a more sensitive way to meet human and functional needs than in the contemporary time (Youssef Hoteit, 1993).

To this regard, scholars have insisted on studying and analyzing urban form together with the socio-cultural context, as they are two aspects of one phenomenon. For long, urban morphology was seen as a tool for understanding the creation and transformation of the urban form. Morphological analysis were undertaken to understand the historical roots and the development process of the built environment as well as to identifying the constituent parts that compose a city today, either on the urban or on the architectural levels, in addition to that, highlighting the motivations behind the evolutions and transformation of the urban fabric. However, urban morphology 
must be a multidisciplinary approach that associates different perspectives for a deeper reading and understanding of the urban form. (Moudon, 1997b).

Nablus' is a historical Palestinian city, which has a very high cultural value. Since its establishment, it passed through many urban transformations as a response to several historical and cultural changes. Today, the city has a vital and lively historic center, where people live and undertake several commercial and trade activities. However, these days, the city urban fabric faces several urban challenges either by development and rehabilitation projects or even by annulation. Nevertheless, throughout time the city has always showed flexibility in adjusting changes for each historical period, while keeping signs of each of them. So far, when all the urban development project push forward its plan, reading the city urban morphology gives the opportunity to understand not just the current urban form but further' it can be a tool for better understand and perceive the urban fabric for further promoting urban transformation.

\section{Methodology}

For a systematic reading of Nablus urban form, this paper highlights the main historical developments and their influence on the transformation of the urban fabric. Moreover, in order to read the urban form, the study conducted an urban morphological analysis on both urban and architectural levels in Nablus' old town, resulting in an updated survey that takes in consideration street hierarchy, plot distribution and residential quarter structure. On the one side, this analysis wishes to explain the built environment of Nablus, showing the roots of its establishment and transformation. Meanwhile, it hints on the relation between culture and urban fabric. This understanding contributed to have a more accurate perception of the city tissue and the roles behind its metamorphosis. Moreover, it highlights some principles that can be useful for thinking about further development. This composition of the urban fabric explains the planning continuity in Islamic cities. It is not enough to see the old town as an artefact but as a structure that contains a complex of meaning and value that lead to constructing it (Nasser, 2003).

\section{Nablus historical background}

Nablus is one of the oldest Palestinian cities. It is located in the north, on a strategic position in a narrow valley between two high mountains, making it the most important opening in a mountainous range. This position has always granted the city a lot of importance as it became not just a junction for several ancient trade roods, but also a cradle for different civilizations, which obviously influenced the society's culture as well as its urban fabric. The history of Nablus goes back thousands of years ago (Al Fani, 1999). Although the current urban fabric reflects a typical example of an Arab-Islamic city in its unique urban form and architecture, it has kept different signs from each historical period, collecting many valuable buildings spreading in its fabric.

In the middle of the third millennium $\mathrm{BC}$, the Canaanite established the first permanent human settlement in Nablus (Al Fani, 1999). Yet, the current location goes back to the Roman time, when the Emperor Vespasian destroyed the old city and built a new one in the middle of the first millennium around 72-73 CE, called Flavian Neapolis. The Roman city developed on three different stages as many Roman signature buildings were added to its urban structure, such as a theatre, a hippodrome, a basilica, and thermal baths (Tuqan e al, 2011).

Later in $636 \mathrm{AC}$, the Arabs conquered the city and from that time on, it continued under different Arab-Islamic rule, namely Ayyoubed followed by the Mameluke, and eventually the Ottoman rule, except for a crusader interruption in the 12th century. During these times and due to the pronunciation of the word "Neapolis", it later became "Nablus". So, under such different Islamic periods, Nablus flourished and grown, not just as an important commercial-trade center, but also as a producer for several goods, notably soap and olive oil. Socially speaking, its population was a mix of Muslims, Christians and Samaritans (Tuqan et all, 2011). 


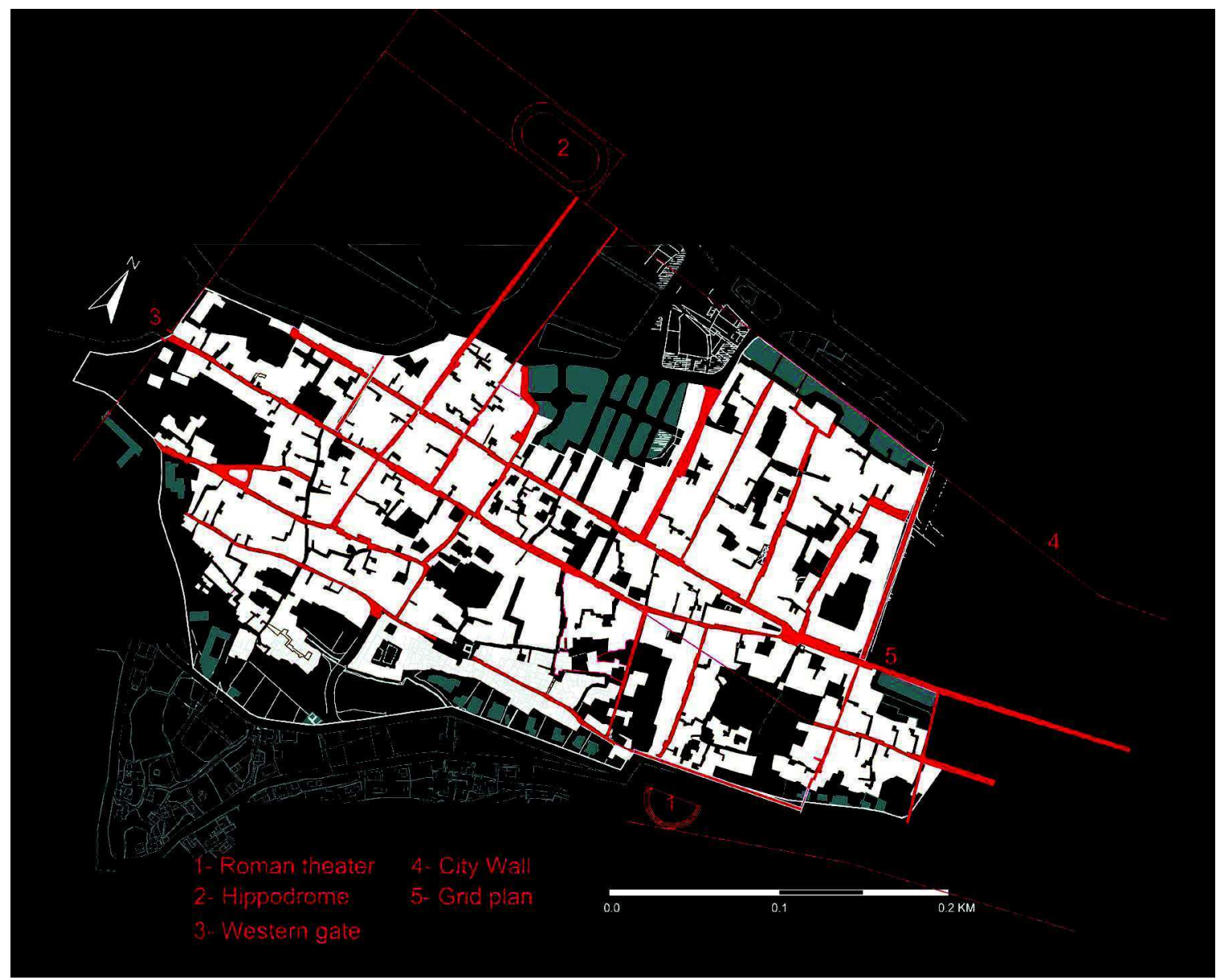

Figure 1.

Roman street layout of Flavian Neapolis (Nablus), according to Nablus, Enduring Heritage and Continuing Civilization. 2011. [6]

However, after the collapse of the Ottoman Empire, the city went under the British mandate and, in 1927, it was hit by a major earthquake, which destroyed a great part of its urban fabric and many of its historical architecture and landmarks were lost forever. This catastrophic event led to an expansion of the city beyond its traditional historic borders. Between 1948 and today, the city lived under different political scopes: from Jordanian rule to Israeli occupation and current Palestinian administration.- More recently, , the city has witnessed an unstable political situation, with a climax in 2002, year of another invasion and consequent destruction of the historic center, severely affected (Al-Dabbeek et al, 2002).

\section{From a rigid grid to an organic plan}

Like most of the Roman cities, Nablus was first established based on a grid plan that consisted of an east-west main axis called Decumanus maximus, passing through the old town and intercepted at right angles by many secondary street, dividing it almost into equal blocks (Figure 1). The Roman domination of the city saw three stages. The first was the construction of three quarters in the south; then, around 131 AD, Emperor Hadrian built another three quarters in the south; and finally, Emperor Phillip expanded the city to the west in 244 AD and added a new quarter. However, the trace of the Roman plan can be noticed in the present street network and several archeological remains spread all over the city (Tuqan et al, 2011).

After $636 \mathrm{AD}$, when Arab rulers conquered the city, Islamic culture was slowly inserted in the society and affected the urban fabric (Tuqan e al, 2011). Gradual transformations 


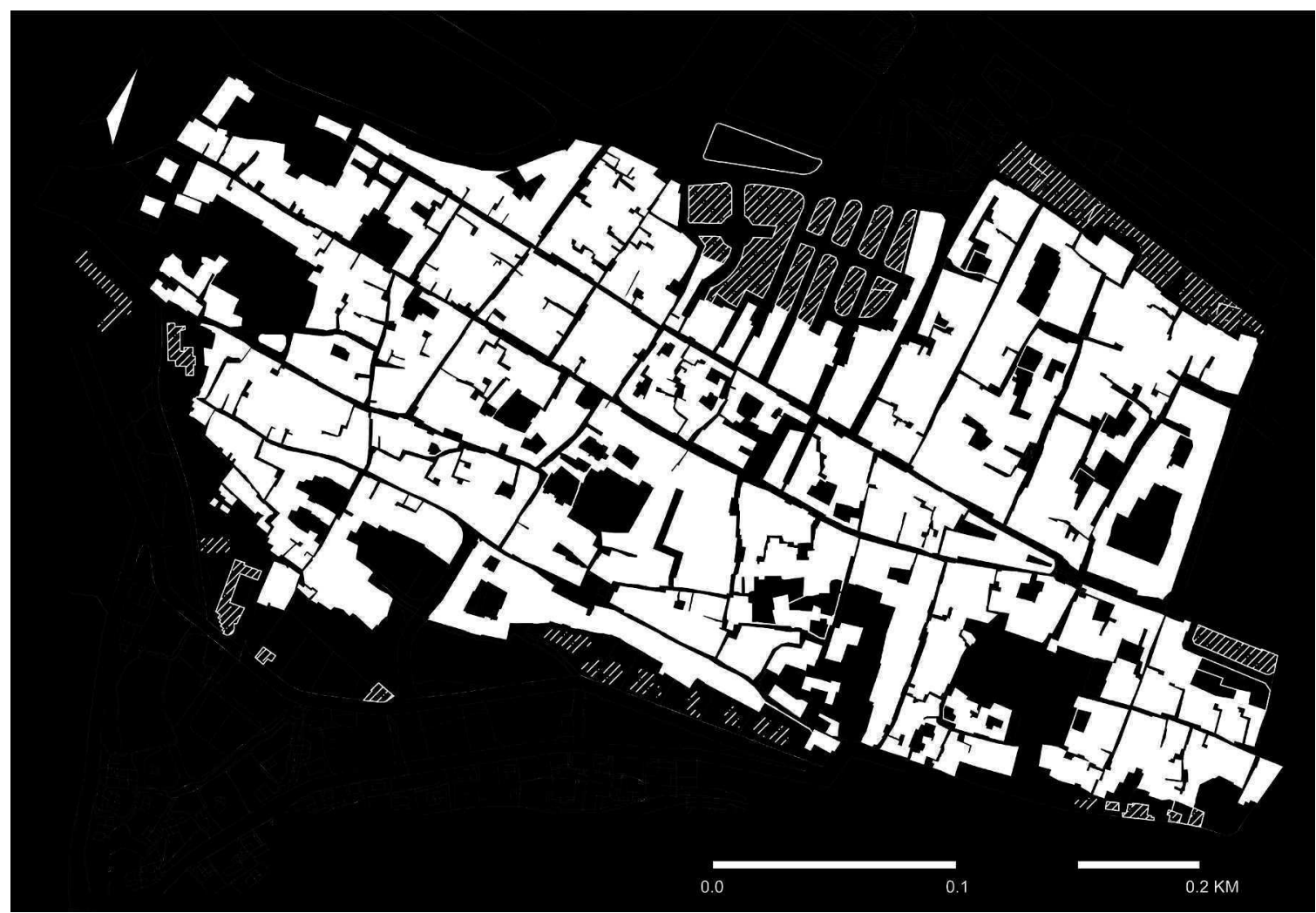

Figure 2.

The existing urban fabric of Nablus old town

started to occur in the city to fit novel cultural and functional requirements since the transformation occurred in the frame of the Roman urban layout. Common rules extracted from the Islamic culture, such as privacy and respect to the others right, regulating the main public and private spaces, led to major urban/ architecture transformation and resulted in a unique arrangement of dense and cluster urban fabric (Hakim, 1986). Thus, streets straightness started to bend and in the residential quarters, they were even closed with houses gathering around a dead end artery forming a small square called "Housh". As a result, a strong rigid grid plan was transformed into an organic and flexible one in Nablus plan (Petruccioli and Pirani, 2002). (Figure 2)

Today, Nablus urban fabric is still composed of six residential quarters (Figure 3), having two main commercial streets passing the city east-west; meanwhile, significant architecture emerged, whether public, religious, residential or symbolic monuments such as mosques, traditional soap factories ("Sabannat"), Ottoman palaces, churches, Turkish baths
("Hammamat"), Caravanserais ("Khanat") and extended family houses ("Housh")(Arafat, 2012). (Figure 4)

Space hierarchy and the "Housh", a cultural urban print

On the urban level, it is possible to observe two main characteristics: first the variation of the spatial hierarchy; secondly, the transformation inside the residential quarter to form the semiprivate square called "Housh".

Space hierarchy varies from openly public in the commercial area frequented by everybody, to exclusively private in residential areas, which is reserved for the local inhabitant. These act as devices serving the social order in its desire for privacy, exclusion and filter of people's movement and accessibility. Between them lies a 'buffer' zone that can be considered as a semi-private or semi-public. Each level of space hierarchy has its arrangement and rule of transformation, character, function, width, architectural elements and level of accessibility, which are all specific to differentiate these 


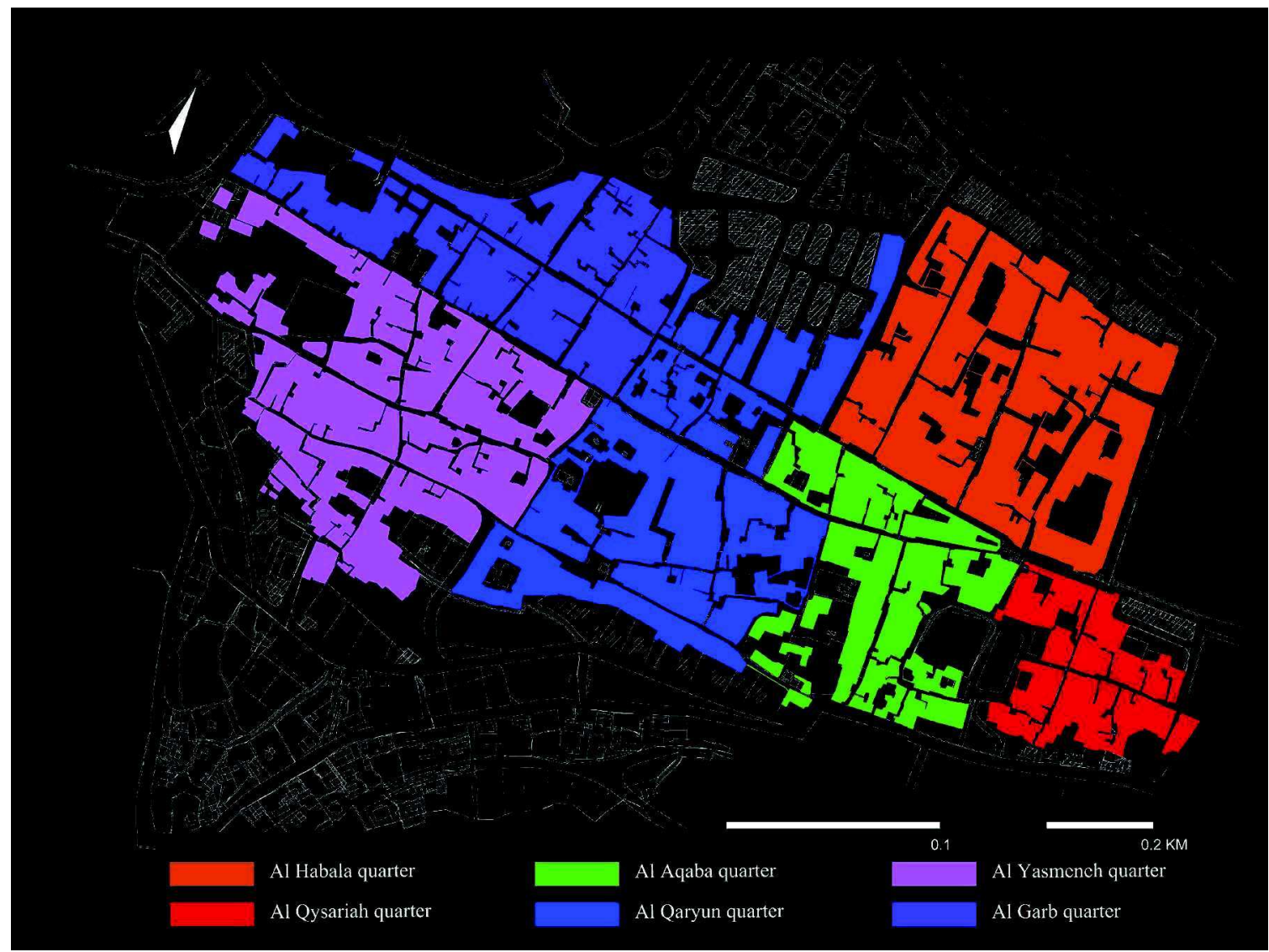

Figure 3.

Quarters in Nablus old towns.

areas and serve its order (Taher et al, 2015). (Figure 5)

The two main public streets extend eastwestwards through the entire city. Located on the trace of the old roman main streets, they host the main commercial center ("souk") and provide a place for economic, social, and cultural activities. These two streets are characterized by their openness, light and vitality, a big part of them being covered to provide protection. Buildings on these streets are multi-stored; often-residential units are placed on the first floor with indirect entrances from a side entrance or through a set of stairs. These major canals connect important city elements such as public baths, the market or the main mosque. (Figure 6)

Meanwhile, another secondary street network, varying from public to private, connects different quarters. The semi-private/ public spaces are another level of hierarchy connecting both public and private spaces. In most of the cases, they serve a light commercial use. Buildings on these streets are multi-stored. Often residential units are placed on the first floor with indirect entrances from a side entrance or through a set of stairs.

On the contrary, the nature of the residential street - cul-de-sacs - is different. Mainly they are private streets within residential quarters. Their width is narrower than the public street, allowing for the neighborhood residents only. The private street function within a quarter is played by a "Housh" most of the times. These lanes work as filter corridors. (Figure 6)

From main streets to cul-de-sacs leading to each house, Islamic urban culture is significantly more related to social aspects of private life than to geometrical questions of regularity. "Housh" in Nablus show a tendency to conduct the pedestrian towards less public and more private areas of circulation. On the one hand, it grants accessibility for residents and, on the other, it restricts mobility by keeping strangers and outsiders out and ensuring safety and privacy for its residents. Residential streets act 


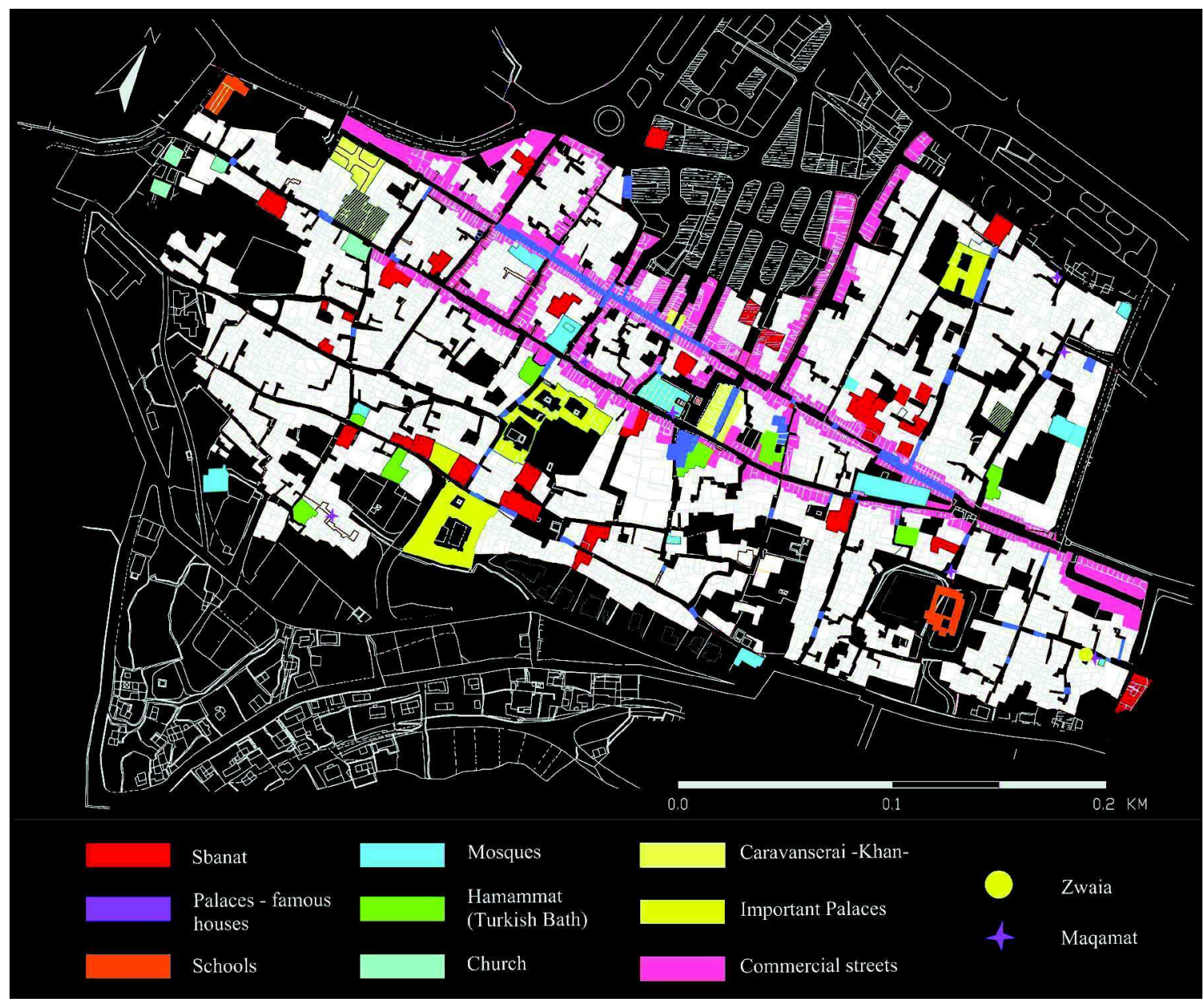

Figure 4.

Land use map in Nablus old town.

as devices serving the social order in its desire for privacy and exclusion, serving as platforms for social activities among neighbors and providing safe sheltered areas (playgrounds) for children to play, for example.

This distinguishable transformation has occurred in the spatial configurations inside the residential quarters. Houses plans have evolved taking into account privacy and neighbor's rights as main urban criteria. In the same arrangement, groups of houses were gathered around such semi-private space, and probably resulting from the closure of an open street or square to serve the privacy and intimacy purposes. Traditionally, it was shared by people from the same family and gets the family. However, the "Housh" as a semi-private space can be considered an outside extension of the houses themselves, used as a garden or an exterior space, where many private and social activates can take place. Besides, it provides a safe place for children to play under the eyes of a monitor.

On the architectural level, obviously, residential spaces referred to the social criteria too. The application of these criteria is sufficiently flexible though, having been considerably affected by neighbors' agreements, ownership, personal desire or functional and contemporary necessities. Houses plans have also evolved to consider privacy and neighbor's rights. Privacy is reflected in the building composition and orientation towards internal spaces (courtyard), while its openings were minimum to the streets. When that happens, they are high or small or treated with architectural elements to keep the internal privacy. Thus, behind the walls, a new private world can be found. So, whereas the public space belongs to everyone, stepping 


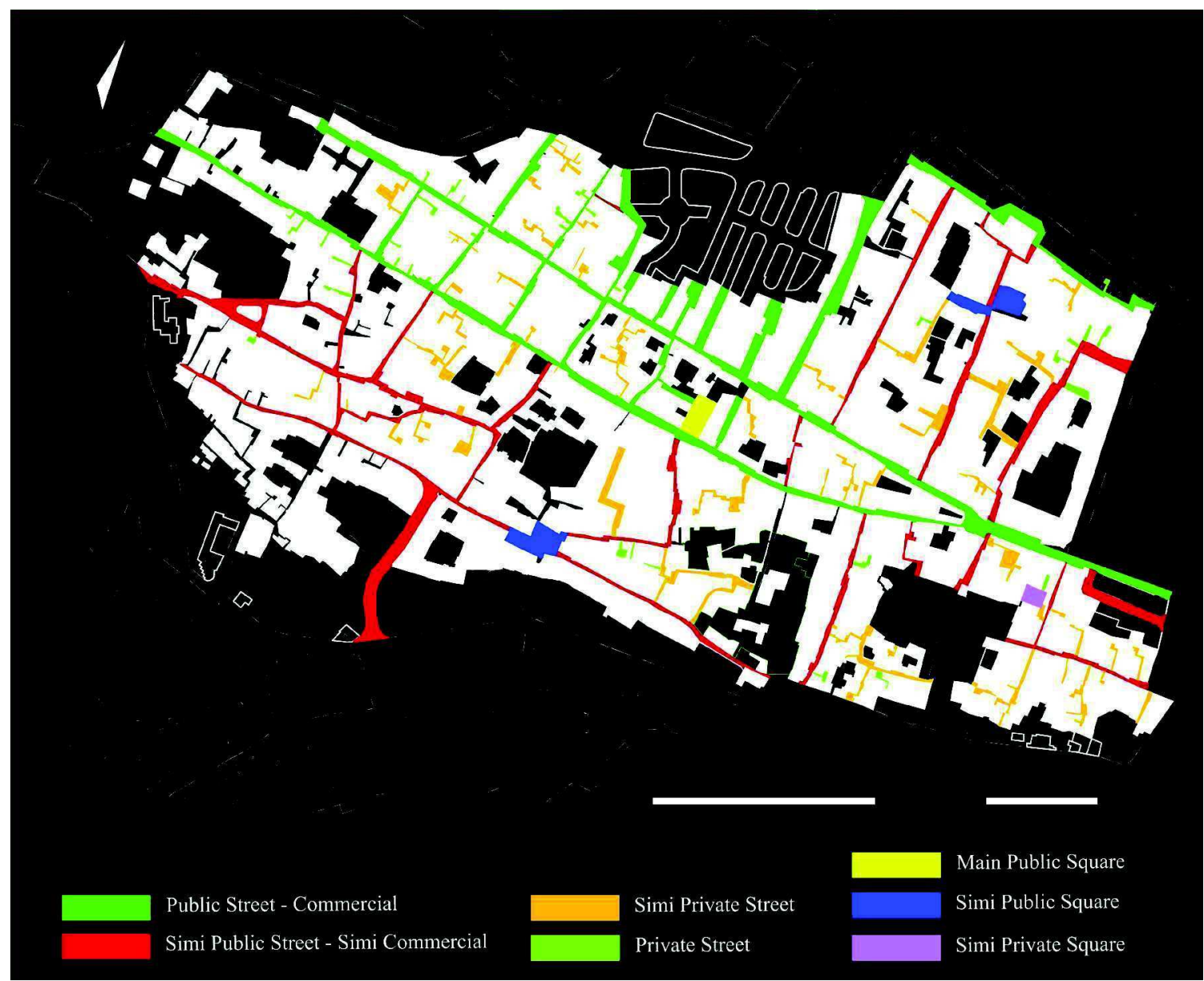

Figure 5

Nablus Streets Hierarchy.

inside a house gate means discovering a new world only accessible to residents or guests.

\section{Conclusion}

Today, the urban fabric of Nablus old town is the sum up of all of the historical layers as well as the interaction between people and their place. The old town was developed through different periods of civilization. Not just the social, cultural, economic changes have affected its urban form, but also natural and manmade disaster had influence on its urban fabric. From the roman grid plan, the city was transformed to suit Muslims culture after the 7 th century AD. However, centuries of Islamic cultural domination have endured a continuous process of adaptation of the classical urban heritage as a response to cultural and social requirements. Since then, socio-cultural criteria led a profound urban transformation while keeping the trace of the original city.

The field survey shows that the urban fabric of Nablus can be understood in the frame of a tight dialogue between social behavior and the traditional built environment, which generate the source of value that legitimizes its physical structure. This frame allows the city to flexibly adapt to peoples cultural and functional needs and recreate its identity. Privacy and respect to the neighbor right were among the main principles that affect the urban morphology of the city: residential quarter street character, function and levels of accessibility.

Cultural urban history can play a fundamental tool and resource for reconstruction processes by reading the city urban morphology. It is important to advocate for a concerned idea of intervention, especially following urban annihilations. In fact, from 'urbicide' to recent economic challenges, any further development 


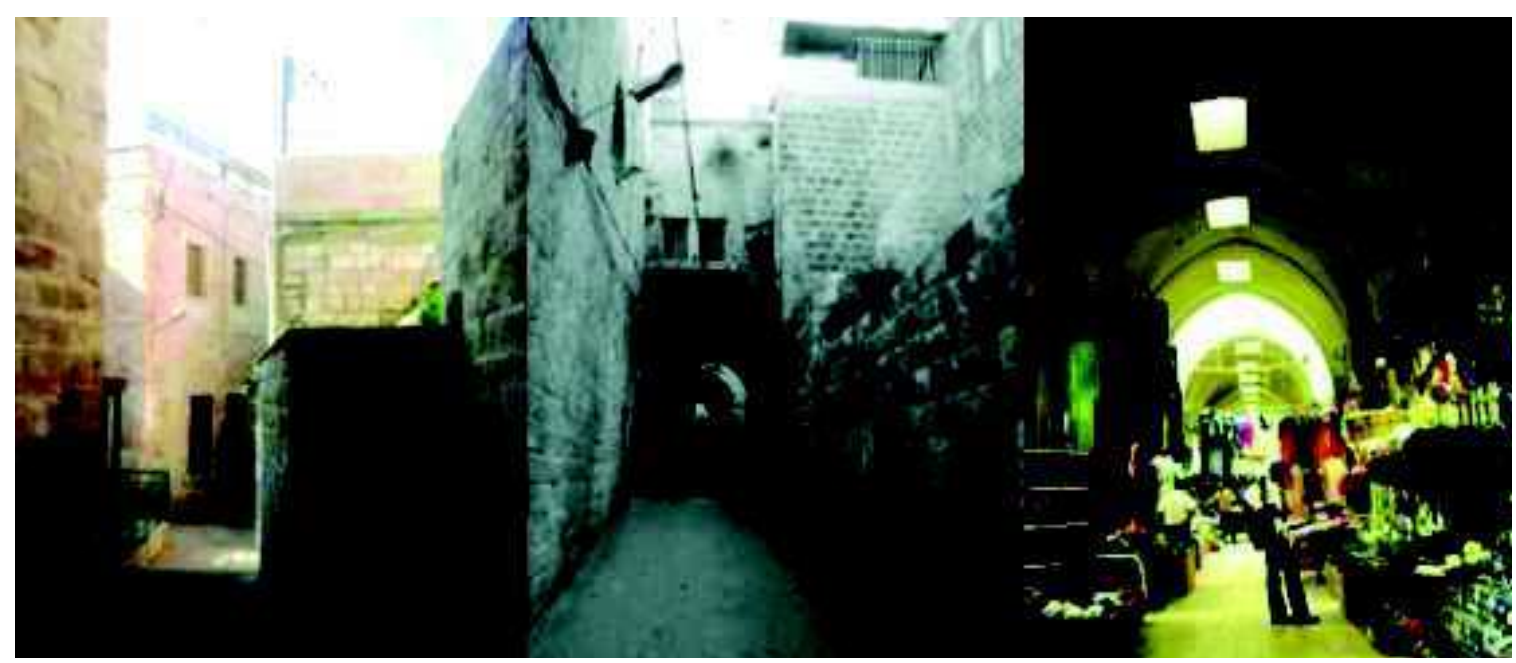

Figure 6.

left: "Housh"; middle: Semi Public street; right: Main commercial street "Souq".

or rehabilitation process should embrace a strong cultural vector in its method, the only way to guarantee a smooth social continuity. Regarding this, socio-cultural criteria work as a paradigm to inform the transformation and this couldn't be more true in Nablus' old town.

\section{References}

Al-Dabbeek, e. M. Amad, e. S. Assi, h. A. Yameen. (2003). Post - disaster damage assessment for the city of Nablus, " third Architectural Conference: Endangered Cities (Vol. 29).

AL Fani, I. 1999. Nablus in Roman and Greek civilizations. Nablus municipality. Palestine

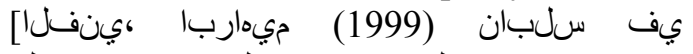

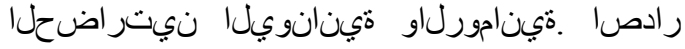

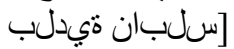

Arafat, N. (2012) Nablus: City of Civilizations (CHEC Cultural Heritage Enrichment Center, Nablus).

Assi, E. (2004) Transformation and Appropriation of Of Public Spaces, the Case of "Sahet Alqaryoun' in Historic City of Nablus (An-Najah University, Palestine).

Hakim, B. S. (1986) Arabic-Islamic Cities: Building and Planning Principles (KPI, London).

Meyer, J. (2012). A Dutch Design Model City, a Question of Historical Continuity,
Authenticity and Sustainability.

Moudon, A. V. (1997). Urban Morphology as an Emerging Interdisciplinary Field. Urban Morphology, 1(1), 3-10.

Taher, M., \& Correia, J. (2015). Streets in Nablus old town: repositories for cultural identity and collective memory. In International Multidisciplinary Scientific Conferences on Social Sciences and Arts, SGEM 2015 (pp. 607-614). SGEM 2015.

Nasser, N. (2003). Cultural continuity and meaning of place: sustaining historic cities of the Islamicate world. Journal of Architectural Conservation, 9(1), 74-89.

Noghsan-Mohammadi, M.-R. (2001). A quest in urban morphology: an analytical approach in formation and transformation of a traditional city: with special reference to case of Yazd, Iran.

Petruccioli, A. and Pirani, K. K. (2002) Understanding Islamic Architecture (Routledge Curzon, London/New York).

Relph, E. (1976). Place and placelessness (Vol. 67). Pion London.

Tuqan, S. and Abdul Hamid, A (2011) Nablus enduring heritage and continuing civilization (Welfare Association, Jerusalem).

Youssef Hoteit, A. (1993) Cultura, espacio y organización urbana en la ciudad islámica (Instituto Juan de Herrera, Madrid). 